\title{
Crocking Fastness Properties of Annatto (Bixa Orellana) Dye on Cotton Mordanted with Eco-Friendly Mordants and Post-Treated with Various Dye Fixing Agents
}

\author{
R. Prabhavathi" ${ }^{*}$ A. S. Devi, D. Anitha and A. Padma
}

Department of Apparel and Textiles, University of Acharya N.G Ranga Agricultural University Advanced Post Graduate Centre Lam, Guntur 522034 (Andhra Pradesh), India

*Corresponding author

\section{A B S T R A C T}

Extraction of natural dyes for the coloration of textile substrate is one the most important research area to the researchers. These dyes are considered to be very good for their colour experimentation quality, excellent for their endurance and soft lustrous colouring. They do not create any pollution problems as they are applied with simple chemical reactions. The wide verities of exotic shades produced by natural dyes are parallel with the synthetic range and hence can replace them with ease. Natural dyes are being considered as a more

\section{Keywords}

Annatto Natural Dye;

Mordant; fixing agent;

Extraction; Dyeing; dry

crocking; Fastness grades

Article Info

Accepted:

22 May 2018

Available Online:

10 June 2018 environmentally friendly substitute for synthetic dyes. The major advantage of natural dyes is the fact that they are produced from renewable sources. Among the few drawbacks of natural dyes low colourfastness property is one. It was tried to improve the Crock Fastness and perspiration fastness Properties of Annatto natural dyed cotton with ecofriendly dye fixing agents. In this research, after mordanted and dyed samples were treated with fixing agents which are helped in fixation of natural dyes on fabric. The 100 percent cotton fabric was selected and desized to remove starch from fabric. Then the fabric was pretreated with morobalan solution for 24 hours. As mordant, Potash Alum [K2A12 (SO4)3.24H2O], Stannous Chloride (SnCl2) and Ferrous Sulphate (FeSO4) were used. Here pre-mordanting was used for mordanting the fabric. The mordanting procedures were followed same for all the experiments. The treatment runtime was 30 minutes at $60^{\circ} \mathrm{C}$. After mordanting each sample fabric was dyed with annatto seeds dye extraction for 45 minutes. After dyeing, all the samples were post-treated with five eco-friendly dye fixing agents such as alum, ammonia, lime juice and calcium chloride. Five percent fixing agent was selected and kept the dyed fabric in the solution for 30 minutes. Finally the fabric samples were cold rinsed and soaping was done and dried. Finally the color fastness like Color fastness to crocking and Color fastness to perspiration were checked and found satisfactory result.

\section{Introduction}

Nature provides rainbow colors that show up in everyday lives. The art of making dyes from plants dates back for centuries. When settlers first came to America, it was necessary to import their favorite dyes and fabrics. After years of experimenting they learned to use plants for making other suitable colors. Those colors and the plants they are made from 
survive still now. There are many flowers, berries, bark, leaves, nuts and roots that will yield dye Devi et al., 2001. Since natural dyes are biodegradable and less toxic and allergenic than synthetic dyes, they are mostly environmentally friendly dyes Samantaa et al., 2009. Natural dyes obtained from renewable resources of nature, such as plant and animal, although Natural dyes from minerals of the earth are also known. Colouring matter derived from different organs of a plant, such as root, leaf, bark, trunk or fruit are known as vegetable dyes; while the colouring matter obtained from the animal kingdom such as lac, cochineal and kermes are known as animal dyes Bechtold et al., 2006 Colouring matters obtained from various inorganic metal ores and metal salts are known as mineral dyes. Natural dyes find application chiefly for colouration of food, drugs, cosmetics and textile. Some quantities of dyes are also used for colouration of paper, leather, shoe-polish, candle, wood etc. Use of natural dyes for colouration of textile is practiced since early days. After the synthesis of Mauveine by William Henry Perkin and its subsequent commercialization, the use of natural dyes receded and the position continued to be much the same until in the recent past growing consciousness about environmental preservation and control of pollution and conventional wisdom and belief regarding environment friendliness of natural dyes have renewed interest for use of natural dyes for the colouration of textile Kim et.al 2001. The major advantage of natural dye is the fact that they are produced from renewable sources. There are some technical drawbacks of natural dtes resenting complexity of dyeing and fastness properties. Few dye auxillaries such as dye fixing and leveling agents sometimes help in proper and uniform fixation of dyes on fabric (Gulrajani et al., 1993).

In this study, cotton fabrics were dyed with natural dyes extracted from Annatto seeds, by use of conventional method. Before dyeing process, firstly the starch was removed from cotton and then pretreatment with myrobalan was given for better dye up-take. Then the pretreated with myrobalan fabric was mordanted with three eco-friendly mordants such as Alum, Stannous chloride and Ferrous sulphate. After dyeing process, the samples having better colour yield were treated with with five eco-friendly dye fixing agents such as vinegar, alum, ammonia, lime juice and calcium chloride to see if the fastness properties of dyed samples would be increased.

\section{History of Natural Dyes}

Dyeing is ancient art which predates written records. It was practiced during the Bronze age in Europe. Primitive dyeing techniques included sticking plants to fabric or rubbing crushed pigments into cloth. Archaeologists have found evidence of textile dyeing dating back to the Neolithic period. In China, dyeing with plants, barks and insects has been traced back more than 5,000 years. Throughout history, people have dyed their textiles using common, locally available materials, but scarce dyestuffs that produced brilliant and permanent colors such as the natural invertebrate dyes, Tyrian purple and crimson kermes, became highly prized luxury items in the ancient and medieval world. Plant-based dyes such as woad (Isatis tinctoria), indigo, saffron, and madder were raised commercially and were important trade goods in the economies of Asia and Europe. Across Asia and Africa, patterned fabrics were produced using resist dyeing techniques to control the absorption of color in piece-dyed cloth. Such as cochineal and logwood (Haematoxylum campechianum) were brought to Europe by the Spanish treasure fleets, and the dyestuffs of Europe were carried by colonists to America Melo MJ, 2009. The first use of the blue dye, woad, beloved by the Ancient 
Britons, may have originated in Palestine where it was found growing wild. Western consumers have become more concerned about the health and environmental impact of synthetic dyes in manufacturing and there is a growing demand for products that use natural dyes. The European Union, for example, has encouraged Indonesian batik cloth producers to switch to natural dyes to improve their export market in Europe Siva R, 2007 \&. Ferreira ES, et al., 2004.

\section{Materials and Methods}

\section{Materials}

In this study, plain light weight weaved cotton fabric with was dyed with the natural dye extraction from Annatto seeds, one of the prominent natural dye, based on carotenoid structure is annatto. It is obtained from the pulpy portion of the seeds of the plant Bixa orellana, the chief ingredient of Annatto is bixine $(5,6)$. Eco -friendly mordants such as alum, stannous chloride and ferrous sulphate were selected for the study. A pretreatment with myrobalan was given for better dye uptake. After dyeing process, the samples having better colour yield were treated with five ecofriendly dye fixing agents such as vinegar, alum, ammonia, lime juice and calcium chloride to see if the fastness properties of dyed samples would be increased.

The dye extraction and treating procedures were standardized based on the procedures suggested by AICRP home science-(1997). The treatments were given to the dyed cotton samples and evaluation of treated samples in the terms of colourfastness to crocking and perspiration before and after treatment was undertaken by following and standard procedure laid down by bureau of Indian standard test series IS 768-1956 for colour change and IS 769-1956 for staining using geometric grey scale. The results were analyzed based on the colour fastness of control samples and imparting treatments was estimated to the economic viability of the process.

Alkaline method was suitable for extraction of dye from Annatto seeds. The optimum time for extraction of dye liquor from the seeds of annatto was $60 \mathrm{~min}$. the dye material for concentration of 4 percent was selected. The optimum time for dyeing was $45 \mathrm{~min}$. Cotton fabric was treated with 20 percent myrobalan concentration to increase the tannin deposition which in turn increased the depth of the shade obtained. To improve the colourfastness, 5 percent solution of fixing agent was selected. Based on absorption values depth of the shade and appearance, three concentrations per each mordant were selected. In case of alum 5, 10 and 15 percent and 1, 2 and3 percent concentrations of stannous chloride and ferrous sulphate mordants for cotton were selected for pre-mordanting of cotton fabric.

\section{Dyeing process}

The dyes were extracted from natural sources using alkaline medium as it was found suitable for Annatto dye, the colour was found to be more in alkaline medium than other medium.

An amount of $1 \mathrm{~g}$ of dye/100ml of water was found to give good shades as well as high absorption of Annatto seeds source. Boiling the dye material for 60 minutes and then dyeing the material with 3 percent concentration of dye material for 45 minutes gave good colour depth with Annatto dye. Bright orange shades were produced on cotton with various mordants treatments. Fabric mordanted with alum produced bright orange shades; stannous chloride produced little bright shades than alum. Grayish orange shades were obtained on cotton mordanted with ferrous sulphate. Mordant concentrations of 5,10 and 15 for alum and 1,2 and 3 for 
stannous chloride and for ferrous suphate were selected based on dye absorption and depth of the shade. After dyeing, the samples were post-treated with five eco-friendly fixing agents such as vinegar, alum, ammonia, lime juice and calcium chloride for better colourfastness of natural dyes on cotton. The results of crockfastness were analyzed based on the colourfastness of control samples to find out the impact of the treatments.

\section{Results and Discussion}

Recently, interest in the use of natural dyes has been growing rapidly due to the result of stringent environmental standards imposed by many countries in response to toxic and allergic reactions associated with synthetic dyes. Very few studies were made to improve to improve the colourfastness of these natural dye sources. Therefore, an attempt has been made in this study to improve the colourfastness of Annatto seeds dye on cotton, by using five fixing agents.

\section{Dry crock fastness of Annatto dye on cotton}

The dry crock fastness of annatto dye on cotton mordanted with eco-friendly mordants and treated with various fixing agents. The fastness grades of control showed good to excellent resistance to colour change with good to very good resistance to colour staining due to dry crocking. Alum and stannous chloride mordanted cottons exhibited excellent resistance to colour change except 1 per per cent alum mordanted sample which registered very good resistance. Good resistance to colour change was found in ferrous sulphate mordanted cottons. The resistance to staining was very good in alum mordanted cottons. In case, of stannous chloride and ferrous sulphate modanted cottons, good resistance to staining was noticed. However, 1 per cent stannous chloride mordanted sample showed very good resistance to dry crocking.
Post-treatment with vinegar showed excellent resistance to colour change in all mordanted samples due to dry crocking. Very good to good resistance to staining was found. Alum, Stannous chloride and ferrous sulphate mordanted cottons showed excellent resistance to staining except, 5 per cent alum and 3 per cent ferrous sulphate mordanted cottons which registered very good resistance to dry crocking. When compared to control vinegar post-treated cottons showed improved rub fastness especially in case of ferrous sulphate mordanted cotton.

Alum post-treated cottons exhibited very good to excellent resistance to colour change and staining due to dry rubbing. While, stannous chloride mordanted cottons showed excellent resistance to colour change alum moprdanted cottons showed very good to excellent resistance to colour change due to dry crocking. Ferrous sulphate mordanted cottons showed very good resistance to colur change with very good to excellent resistance to colour staining. However, alum and stannous chloride mordanted cotton exhibited very good resistance to staining except 3 per cent stannous chloride mordanted samples, which showed excellent resistance to colour staining.

Post-treatment with alum showed slightly decreased resistance to colour change in case of alum and stannous chloride mordanted cottons due to dry rubbing over control. However, increased resistance to colour change and staining was found in ferrous sulphate mordanted cottons.

Post-treatment with ammonia showed good to excellent resistance to colour change due to dry rubbing. The resistance to colour staining varied as per the mordant used. Alum mordanted cottons showed good to excellent resistance to colour change and with good to very good resistance to colour staining. Stannous chloride also showed good to 
excellent resistance to colour change with good to very good resistance to staining. Ferrous sulphate mordanted cottons exhibited excellent fastness to colour change and very good resistance to colour staining. When compared to control ammonia treated cottons that were mordanted with alum and stannous chloride did not shown any improvement in resistance colour change. Ferrous sulphate mordanted cottons exhibited slight improvement in resistance to staining over control.

Post-treatment with lime juice exhibited good to excellent resistance to colour change and good to very good résistance to staining in alum mordanted cotton samples. While stannous chloride mordanted cottons exhibited excellent resistance to colour change, ferrous sulphate mordanted cottons showed very good resistance to colour change. All mordanted cottons except 15 per cent alum motrdanted sample, showed very good resistance to staining. However, 15 per cent alum mordanted sample exhibited good resistance to staining. Lime juice post-treated cottons did not show any improvement in dry crock fastness incases, of alum and stannouos chloride mordanted samples except 5 per cent alum mordanted cotton. However, 5 per cent alum mordanted cottons showed slight increase in resistance to colour change over control. Decreased resistance to staining was absorbed in alum and stannous chloride mordanted samples. Slightly increased resistance to staining was observed in ferrous sulphaste mordanted cottons over control.

Treatment with calcium chloride showed good to excellent resistance to colour change with fair to very good resistance to staining due to dry crocking. Alum mordanted cottons had registered good to excellent resistance to colour staining, while stannous chloride mordanted cottons exhibited good to excellent resistance to color change with very fair to good resistance to colour staining. Ferrous sulphate mordanted cottons showed good resistance to colour change and staining over control. Decreased resistance to staining was observed in alum and stannous chloride mordanted samples. However, slight increase in resistance to staining was observed in ferrous sulphate mordanted cottons over control. Treatment with calcium chloride had not registered any improvement in dry crocking over control.

\section{Wet crocking fastness of annatto dye on cotton}

The wet crocking fastness of annatto dye on cotton mordanted with eco-friendly mordants and post- treated with various fixing agents.

The fastness grades of Annatto dye control sample exhibited very fair to good resistance to colour change and poor to fair resistance to staining due to wet crocking. Alum and stannous chloride mordanted cottons showed very fair to good resistance to colour change and poor to fair resistance to staining. Ferrous sulphate mordanted cottons showed very fair resistance to colour change and fairly poor resistance to staining.

Post- treatment with vinegar exhibited very good to excellent registration to colour change due to wet crocking when registration to staining was observed from good to very good. All mordanted samples except 5 per cent alum, 1 per cent stannous chloride and 1 per cent ferrous sulphate mordanted samples exhibited excellent resistance to colour change due to wet crocking. The fastness improved with the increasing mordant concentration. Majority of the alum and ferrous sulphate mordanted cottons showed very good resistance to staining. Good to very good resistance to staining was found in stannous chloride mordanted cottons. All the mordanted samples show improved fastness over control. 
Table.1

Medium of extraction
Aqueous
Acedic
Alkaline

Annatto

0.062

0.063

$0.406^{*}$

*indicates the selected extraction medium

Table.2 Dry Crock Fastness Fastness Properties of Annatto (Bixa Orellana) Dye on Cotton

Dye percentage: $3 \%$

Mordants: Alum, stannous chloride, ferrous sulphate

Extraction medium: alkaline alkali conc: $1 \mathrm{~g} / 100 \mathrm{ml}$.

Dye Extraction Time: $60 \mathrm{~min}$.

Mordanting time: $30 \mathrm{~min}$.

Dyeing time: $45 \mathrm{~min}$.

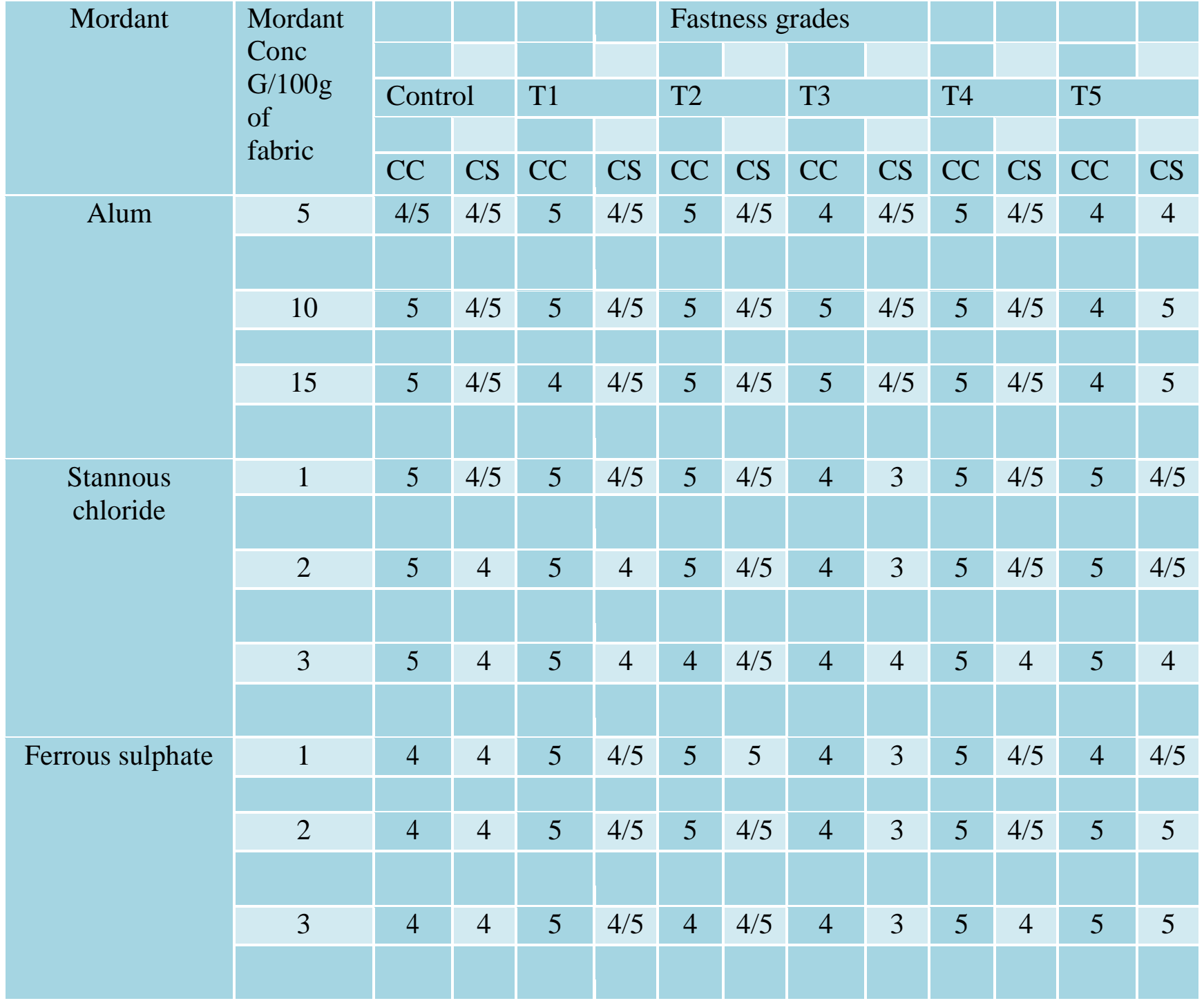

Note: vinegar $(\mathrm{CH} 3 \mathrm{COOH})$, T2-Alum (AlK (SO4)2, T3-ammonia (NH3), T4- Lime juice, T5- calcium chloride $(\mathrm{CaCl} 2)$. 
Table.3 Wet crocking fastness properties of Annatto (bixa orellana) dye on cotton

Dye percentage: $3 \%$

Extraction medium: alkaline Alkali conc. $1 \mathrm{~g} / 100 \mathrm{ml}$.

Mordanting time: 30 min.

\begin{tabular}{|c|c|c|c|c|c|c|c|c|c|c|c|c|c|}
\hline \multirow[t]{3}{*}{ Mordant } & \multirow{3}{*}{$\begin{array}{l}\text { Mordant } \\
\text { Conc } \\
\mathrm{G} / 100 \mathrm{~g} \\
\text { of } \\
\text { fabric }\end{array}$} & & & & & \multicolumn{4}{|c|}{ Fastness grades } & & & & \\
\hline & & \multicolumn{2}{|c|}{ control } & \multicolumn{2}{|l|}{$\mathrm{T} 1$} & \multicolumn{2}{|l|}{$\mathrm{T} 2$} & \multicolumn{2}{|l|}{$\mathrm{T} 3$} & \multicolumn{2}{|l|}{ T4 } & \multicolumn{2}{|l|}{ T5 } \\
\hline & & $\mathrm{CC}$ & $\mathrm{CS}$ & $\mathrm{CC}$ & CS & $\mathrm{CC}$ & CS & $\mathrm{CC}$ & $\mathrm{CS}$ & $\mathrm{CC}$ & $\mathrm{CS}$ & $\mathrm{CC}$ & $\mathrm{CS}$ \\
\hline \multirow[t]{3}{*}{ Alum } & 5 & 4 & $2 / 3$ & $4 / 5$ & 4 & 5 & $4 / 5$ & 3 & 4 & 4 & 4 & 5 & 3 \\
\hline & 10 & $3 / 4$ & 3 & 5 & $4 / 5$ & 5 & $3 / 4$ & 4 & 4 & 5 & 3 & 4 & 3 \\
\hline & 15 & $3 / 4$ & 3 & 5 & $4 / 5$ & 4 & 4 & 5 & 4 & 4 & 3 & 5 & 3 \\
\hline \multirow[t]{3}{*}{ Stannous chloride } & 1 & 4 & 3 & $4 / 5$ & 4 & 5 & $4 / 5$ & 4 & 4 & 5 & 3 & 4 & $3 / 4$ \\
\hline & 2 & $3 / 4$ & $2 / 3$ & 5 & 4 & 5 & $4 / 5$ & 5 & 3 & 5 & 3 & 5 & $3 / 4$ \\
\hline & 3 & $3 / 4$ & $2 / 3$ & 5 & $4 / 5$ & $4 / 5$ & 4 & 5 & 3 & 5 & 3 & $3 / 4$ & $3 / 4$ \\
\hline \multirow[t]{4}{*}{ Ferrous sulphate } & 1 & $3 / 4$ & $2 / 3$ & $4 / 5$ & $4 / 5$ & 5 & 4 & 4 & $2 / 3$ & 4 & 3 & 3 & 5 \\
\hline & & $3 / 4$ & & & & & & & & & & & \\
\hline & 2 & $3 / 4$ & $2 / 3$ & 5 & $4 / 5$ & 4 & 4 & 5 & $2 / 3$ & 5 & 3 & 3 & 5 \\
\hline & 3 & $3 / 4$ & $2 / 3$ & 5 & $4 / 5$ & 5 & 4 & 4 & $2 / 3$ & 5 & 3 & 3 & 3 \\
\hline
\end{tabular}

Note: vinegar (CH3COOH), T2-Alum (AlK (SO4)2, T3-ammonia (NH3), T4- Lime juice, T5- calcium chloride $(\mathrm{CaCl} 2)$.

Fig.1 Chemical structure of Annatto seed carotenoids and image of annatto seeds (https://www.researchgate.net/figure/Chemical-structure-of-annatto-seedcarotenoids_fig1_260761646)

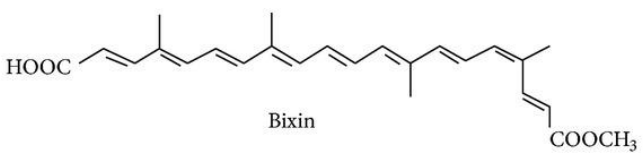

(a)

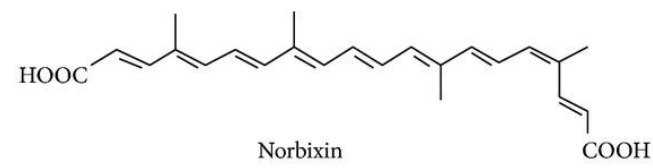

Go

(b)

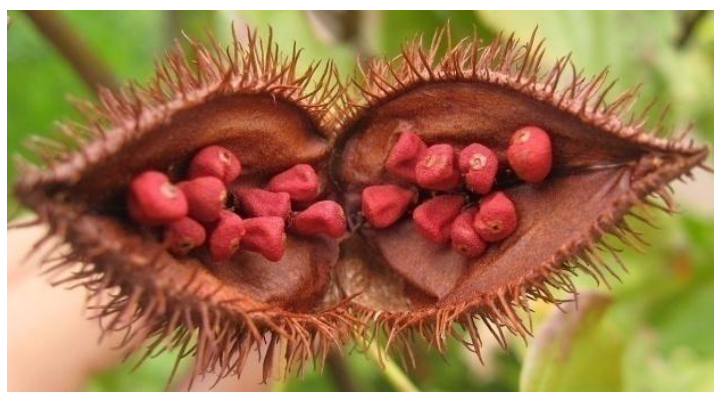


Fig.2

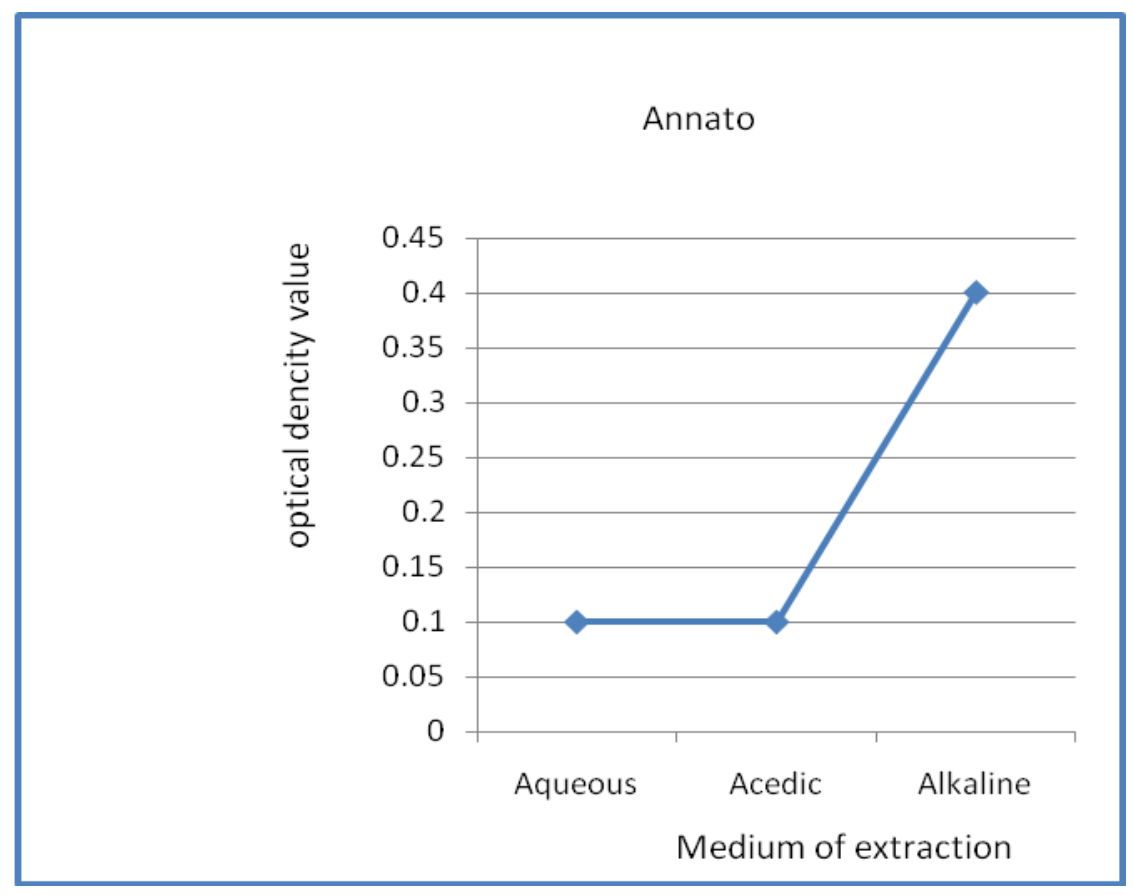

Fig.3 Dry crocking of Annatto Dye on Alum, Stannous chloride and Ferrous sulphate Mordanted $\&$ Treated cottons

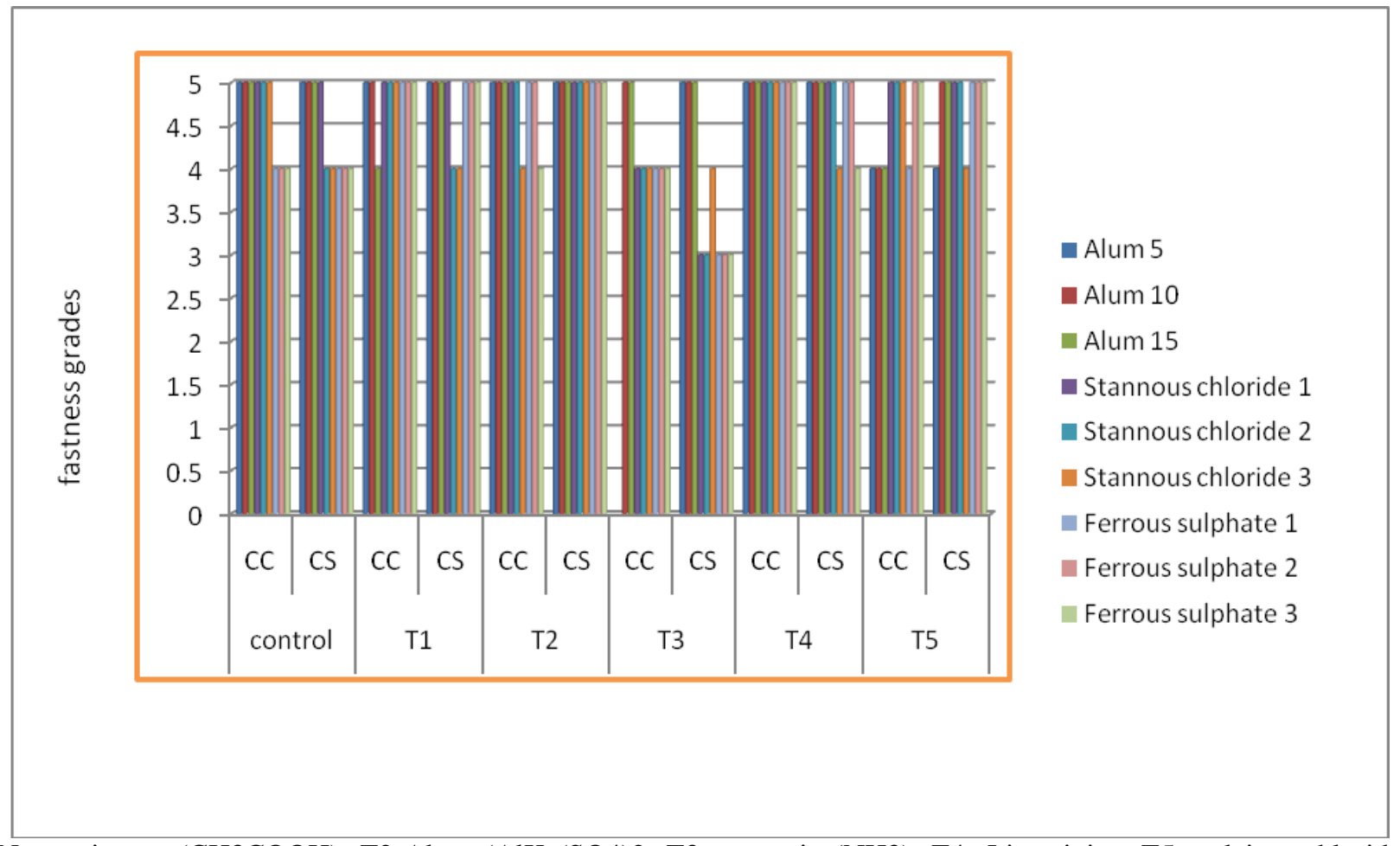

Note: vinegar (CH3COOH), T2-Alum (AlK (SO4)2, T3-ammonia (NH3), T4- Lime juice, T5- calcium chloride $(\mathrm{CaCl} 2)$. 
Fig.4 Wet crocking of Annatto Dye on Alum, Stannous chloride and Ferrous sulphate Mordanted \& Treated cottons

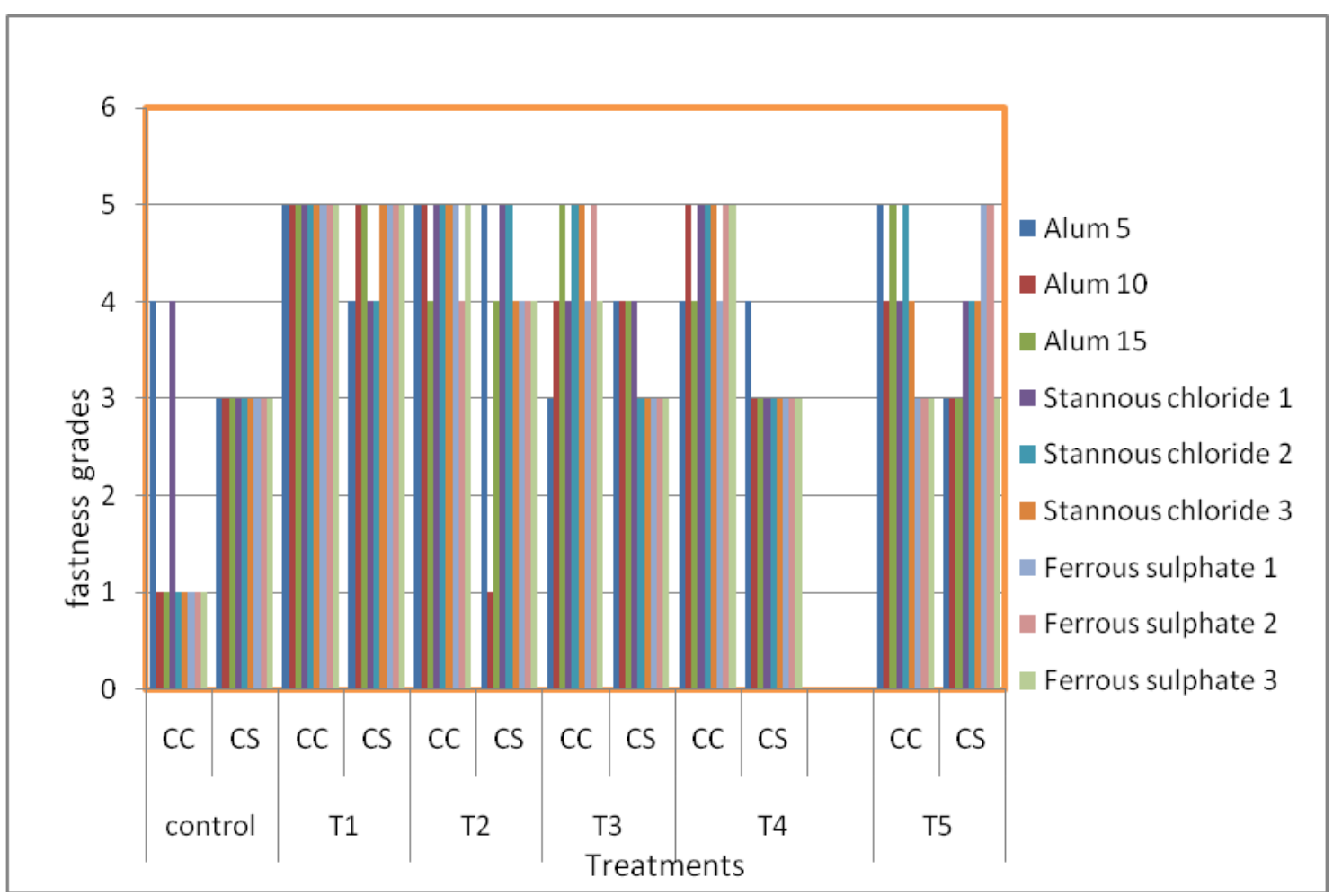

Note: vinegar (CH3COOH), T2-Alum (AlK (SO4)2, T3-ammonia (NH3), T4- Lime juice, T5- calcium chloride $(\mathrm{CaCl} 2)$.

Alum post-treated cottons had registered good to excellent resistance to colour change and very fair to very good resistance to staining due to wet crocking. While good to excellent resistance to colour change was observed in all mordanted cottons, as resistance to staining varied with the mordant it was very fair to very goodin alum mordanted cottons. Good to very good in case of stannous chloride mordanted cottons and good resistance in ferrous sulphate mordanted cottons, and compared to control, posttreatment with alum had contributed for improvement in resistance to colour change and staining in all mordanted samples.

Post-treatment with ammonia registered good to excellent resistance to colour change with fair to good resistance to staining due to wet crocking. All treated cottons exhi9bited good to excellent resistance to colour change. Resistance to staining varied slightly mordant which registered as good resistance in case of alum, fair to good resistance in stannous chloride and fairly poor resistance to staining incase ferrous sulphate mordanted cottons. Almost all cottons fabrics treated with ammonia showed improved fastness over control. However, sample mordanted with ferrous sulphate showed no change in wet crocking fastness.

Post-treatment with ammonia registered good to excellent resistance to colour change with fair to good resistance to staining due to wet crocking. All treated cottons exhi9bited good to excellent resistance to colour change. Resistance to staining varied slightly mordant which registered as good resistance in case, of alum, fair to good resistance in stannous 
chloride and fairly poor resistance to staining incase, ferrous sulphate mordanted cottons. Almost all cottons fabrics treated with ammonia showed improved fastness over control. However, sample mordanted with ferrous sulphate showed no change in wet crocking fastness.

The wet crocking fastness grades of lime juice post-treated cottons had good to excellent resistance to colour change and fair to good resistance to staining. All mordanted cottons, except, 5, 15 percent alum and 1 per cent ferrous sulphate mordanted samples, showed excellent resistance to colour change. Fair resistance to staining was observed in all mordanted samples. Except 1 per cent alum mordanted and 1 per cent ferrous sulphate mordanetd cottons. This showed good resistance however these mordanted samples exhibited good resistance to colour change to staining due to wet crocking when compared to control. Lime juice post-treated cottons showed improvement in resistance to colour change and slightly increased resistance to staining over control.

Post-treatment with calcium chloride mordanted clothes displayed good to excellent resistance to colour change and fair to very fair resistance staining. Alum and stannous chloride mordanted cottons showed good to excellent resistance to colour change, whereas, ferrous sulphate mordanted cottons exhibited good wet crocking fastness.

Alum and ferrous sulphate mordanted cottons exhibited fair resistance to staining and stannous chloride mordanted cottons showed very fair resistance to staining. When compared to control calcium chloride mordanted cottons exhibited increased resistance to colour change due to wet crocking. No change was observed in case of alum and ferrous sulphate mordanted cottons. However, slight increased in resistance to staining was noted in stannous chloride mordanted cottons.

Among the mordanted and post-treated cottons, vinegar post-treated samples showed in increased depth of the shade on cottons mordanted with alum styannous chloride and ferrous sulphate besides providing leveled shades over control.

The dry rub fastness of ferrous sulphate mordanted samples in creased. The wet crocking fastness was increased in all mordanted samples.

The alum post-treated samples produced better shades than control in case of alum and ferrous sulphate pre- mordanted cottons and increased level dyeing was observed in all mordanted samples. The dry rub fastness of ferrous sulphate mordanted samples increased improvement in depth of shade and resistance to staining was found in all mordanted samples due to wet crocking over control.

Post-treatment with ammonia did not register any improvement. Slight improvement was noticed with both dry and wet crocking.

The lime juice post-treated samples exhibited increased in depthn of the shade and contributed for level dyeing in all mordanted samples. The dry crocking fastness was slightly increased with increased colour stain fastness. The dry and wet crock fastness was improved in terms of resistance to colour change and slight increase in resistance to staining in all mordanted samples over control.

Calcium chloride post-treated cottons did not register any change in the shade over control. Majority of the mordanted samples had no improvement in dry crocking with noticeable stains over control. The resistance to colour change showed slight increased in staining 
incase of stannous chloride and ferrous sulphate mordanted cottons due to wet crocking.

\section{References}

Agarwal A, Goel A. Guptha K.C. 1992, optimization of dyeing process of wool with natural dyes obtained from turmeric (curcuma longa), Textile dyer and printer 25 (22): 28-30

Agarwal A, Goel A. Paus S. 1993, effect of mordants on natural dye. In Indian textile journal 103 (4): 110-111.

Agarwal A,Goel A. Guptha K.C. 1992, development of suitable dyeing process for dyeing of wool with natural dyes Henna (Lawsonia inerma), Textile dyer and printer 29 (10): 43-45.

Ali S, Nisar N, and Hussain T, J. Text. Inst., 98, 559 (2007).

Bechtold T, et al., Extraction of natural dyes for textile dyeing from coloured plant wastes released from the food and beverage industry. Journal of the Science of Food and Agriculture. 2006, 86(2): 233-242.

Binita kali and Gogai N cationic fixing agent. The Indian textile journal 108 (9-12) 42-46.

Binitha kali and Gogai N 1998, Cationic fixing agent. The Indian textile journal 108(9-12): 42- 46.

Colour from Nature-silk dyeing Using Natural dyes (SERI-2000) (OXFORD \& IBH Pub. Co.OvtLtd), 2000, 11-88.

Dedhia EM 1998 natural dyes colourage XLV (3): 45-49.

Devi S, katyayini VKLT and Smanthy B S 2001 Annatto -a bright natural colourant for silk. Indian silk 39(12): 22-23.

Devi S, katyayini VKLT and Smanthy B S 2002 Annatto -a bright natural colourant for cotton. Textile Trends XLV (9) 29-33.
Devi S, Katyayini VKLT and sumanthi B.S. 2002optimisation of dyeing procedures. All India co-ordinate research project clothing and textile report, Acharya N.G. Ranga Agricultural University, Hyderabad, 20-40.

Devi S, Katyayini VKLT and sumanthi BS 2002 Afast natural colour for cotton: amaltas. New cloth market 16(5): 13 16.

Ferreira ES, et al., The natural constituents of historical textile dyes. Chemical Society Reviews. 2004, 33(6): 329-336.

Indian standard institute (BIS) book of textile testing 1982 Nanak Bhavan New Delhi PP: 24, 69, 474, 359-543, 550-551, 553, 569-570.

Jothi D. Extraction of natural dyes from African marigold flower (Tagetes ereectal) for textile coloration. AUTEX Research Journal. 2008, 8(2): 49-53.

Kamel M M, El-Shishtawy R M, Yussef B M and Mashaly $\mathrm{H}$, Ultrasonic assisted dyeing: III. Dyeing of wool with lac as a natural dye, Dyes Pigments, 2005, 65, 103-110.

Mairal A K and shah JC 2001, role of some Eco-friendly chaemicals in pre- and after treatments of textiles. Manmade textile in India XLIV N (4): 136-138.

Melo MJ. History of natural dyes in the ancient mediterranean world. Handbook of natural colorants. 2009:3-20

Paul R Jayes MV and Nayak SR 1996, Natural dyes Classification, extraction and fastness properties. Textile dyer and printer 29(22): 16-24

Paul S Sharma A and Grover E, 2002, colourfastness of wool dyed with eco dye Hemelia. Man made textiles in India XLV (4): 324-328.

Rathi D and Krishnan K 1997, use of sequestering agents to improve the fastness properties of natural dyes. Unpublished masters dissertations, university of Mumbai. 
Rette and Lemin 1949, Chemistry of textile auxiliaries Vol. VIII: 80-81.

Saito M 1988, textile research journal 58 (8): 450.

Samantaa AK, Agarwal P. Application of natural dyes on textiles. Indian Journal of Fibre and Textile Research. 2009, 34: 384-399

Sharma B and kalita B 1999 After-treatment of direct dye on cotton fabric. The Indian textile journal 109 (1-4): 64-68.

Sharma B and Kalitha B, 1999, after treatment of direct dye on cotton fabric. The Indian textile journal 109(1-4): 6468.

Singh S, jatin S and Guptha Kc, 1993, a optimization of procedure for dyeing of silk with natural dye madder routes (Rubia Cordi Folia).Colourage 40 (8): 33-36.

Siva R. Status of natural dyes and dyeyielding plants in India. Current Science-Bangalore-, 2007, 92(7): 916.

Teli MD, Nawathe VB and Adivarkar RV 1994 Dyeing of cotton with catechu. Journal of Textile Association. 6: 297299.
Udayini S and jocob M 1988 development of new vegetable dyes for kalamkari painting and to assess their colour fastness property. Colourage 35 (21): 19.

Valianou L, Karapanagiotis I, and Chryssoulakis Y. Comparison of extraction methods for the analysis of natural dyes in historical textiles by high-performance liquid chromatography. Analytical and bioanalytical chemistry. 2009, 395(7): 2175-2189

Vineeth K and Bharthi 1998 eucalyptus yields dye. The Indian textile journal XVIII: $18-20$

WWW.ang.k.fungigrass.ac.at/katzer/engl/bixa ore html o www.pburch.net/dyeing/dyelog.

Zhang X, Laursen RA. Development of mild extraction methods for the analysis of natural dyes in textiles of historical interest using LC-diode array detectorMS. Analytical Chemistry. 2005, 77(7): 2022-

\section{How to cite this article:}

Prabhavathi R., A. S. Devi, D. Anitha and Padma, A. 2018. Crocking Fastness Properties of Annatto (Bixa Orellana) Dye on Cotton Mordanted with Eco-Friendly Mordants and PostTreated with Various Dye Fixing Agents. Int.J.Curr.Microbiol.App.Sci. 7(06): 3009-3020. doi: https://doi.org/10.20546/ijcmas.2018.706.354 